\title{
PERSPECTIVE
}

\section{Assessment of visual acuity in multiply handicapped children}

\author{
R T Mackie, D L McCulloch
}

Assessment and management of visual disorders in children with physical and/or intellectual impairment present a complex challenge to the clinician. A comprehensive review of all aspects of vision care in multiply handicapped children is too diverse to address in a single review. This review will focus on the techniques which have been developed for visual acuity assessment in this challenging population. Conventional acuity tests are often impractical and unsuccessful for achieving a reliable measurement of visual acuity in multiply handicapped children. ${ }^{1}$ Two visual acuity assessment techniques have gained wide acceptance for testing these children, preferential looking (PL) and visual evoked potentials (VEPs). The success rates of completion of these procedures and acuity estimates achieved are compared and discussed.

Multiply handicapped children have a high incidence of nearly all types of disorders affecting the visual system including refractive errors, strabismus, nystagmus, cataract, optic atrophy, optic nerve hypoplasia, defects of the visual field, and cortical blindness. ${ }^{2-9}$ Reported prevalence of visual disorders for different groups of handicapped children is summarised in Table 1. Prevalence for each condition varies widely as studies are based on different populations of handicapped children and different criteria were used to establish the diagnoses. These conditions are not mutually exclusive - for example, $80-86 \%$ of children with cerebral palsy have one or more of the above visual disorders. ${ }^{9} 10$

Table 1 Conditions with multiple handicaps and their associated visual disorders

\begin{tabular}{|c|c|c|}
\hline Handicap & $\begin{array}{l}\text { Associated visual } \\
\text { disorders }\end{array}$ & $\begin{array}{l}\text { Reported } \\
\text { prevalence (\%) }\end{array}$ \\
\hline Cerebral palsy 491011 & $\begin{array}{l}\text { Refractive error } \\
\text { Amblyopia } \\
\text { Strabismus } \\
\text { Nystagmus } \\
\text { Visual field defect } \\
\text { Optic atrophy } \\
\text { Cortical visual impairment }\end{array}$ & $\begin{array}{l}50-64 \\
15-32 \\
50-69 \\
8 \cdot 6-18 \\
1-11 \\
4-10 \\
3 \cdot 1\end{array}$ \\
\hline $\begin{array}{l}\text { Complications of } \\
\text { prematurity }{ }^{12-15}\end{array}$ & $\begin{array}{l}\text { Significant refractive error } \\
\text { Strabismus } \\
\text { Nystagmus } \\
\text { Retinopathy of prematurity } \\
\text { Optic atrophy } \\
\text { Cortical visual impairment }\end{array}$ & $\begin{array}{l}17-32 \cdot 5 \\
9 \cdot 9-50 \\
2 \cdot 4-10 \\
69 \\
2 \cdot 7-20 \\
\star\end{array}$ \\
\hline $\begin{array}{l}\text { Hypoxic/ischaemic brain } \\
\text { injury } 1617\end{array}$ & $\begin{array}{l}\text { Strabismus } \\
\text { Nystagmus } \\
\text { Visual field defect } \\
\text { Optic atrophy } \\
\text { Cotical visual impairment }\end{array}$ & $\begin{array}{l}24 \\
8-8 \cdot 6 \\
36 \\
20 \\
\star\end{array}$ \\
\hline Hydrocephalus 51118 & $\begin{array}{l}\text { Amblyopia } \\
\text { Strabismus } \\
\text { Optic atrophy } \\
\text { Cortical visual impairment }\end{array}$ & $\begin{array}{l}\star \\
\star \\
\star \\
\star\end{array}$ \\
\hline Down's syndrome $^{6} 7111920$ & $\begin{array}{l}\text { Refractive error } \\
\text { Strabismus } \\
\text { Cataract } \\
\text { Keratoconus } \\
\text { Impaired accommodation }\end{array}$ & $\begin{array}{l}30-42 \\
27-36 \\
4-27 \\
\star \\
\star\end{array}$ \\
\hline
\end{tabular}

$\star$ Data not reported
Visual impairment is known to delay and alter both visual and general development. ${ }^{21} 22$ Undetected visual impairment combined with other handicaps is likely to have an adverse effect on development and may lead to an underestimation of intellectual ability. Warburg reports that mentally handicapped children with visual impairment are inappropriately classed as profoundly handicapped more often than sighted children with equivalent levels of mental handicap. ${ }^{23}$ When visual function can be improved by the provision of spectacles and/or visual training to improve fixation and accommodation, social behaviour and motor skills of children at all levels of intellectual impairment have shown improvement. ${ }^{24} 25$ Changes are most evident in the youngest age group. ${ }^{25}$ Therefore, a reliable estimate of visual acuity in multiply handicapped children is important, to improve vision where possible, to monitor visual development, and to quantify the degree and type of visual impairment. This information can lead to appropriate ophthalmological and/or educational intervention which may improve developmental potential.

\section{Preferential looking}

TESTING PROCEDURES

Preferential looking is based on the observation that an infant will look at a striped target in preference to a blank target of equal luminance, when both are presented simultaneously (see Fig 1). ${ }^{26}$ The finest striped target which the infant will consistently fixate, with greater than chance probability, provides an estimate of grating acuity. Conventional PL methods require several target presentations above and below threshold. ${ }^{27} 28$ For each presentation the observer makes a forced choice judgment of the infant's fixation preference (FPL). Operant conditioning employs positive reinforcement to enhance fixing responses (OPL). ${ }^{29}$ OPL estimates of acuity agree well

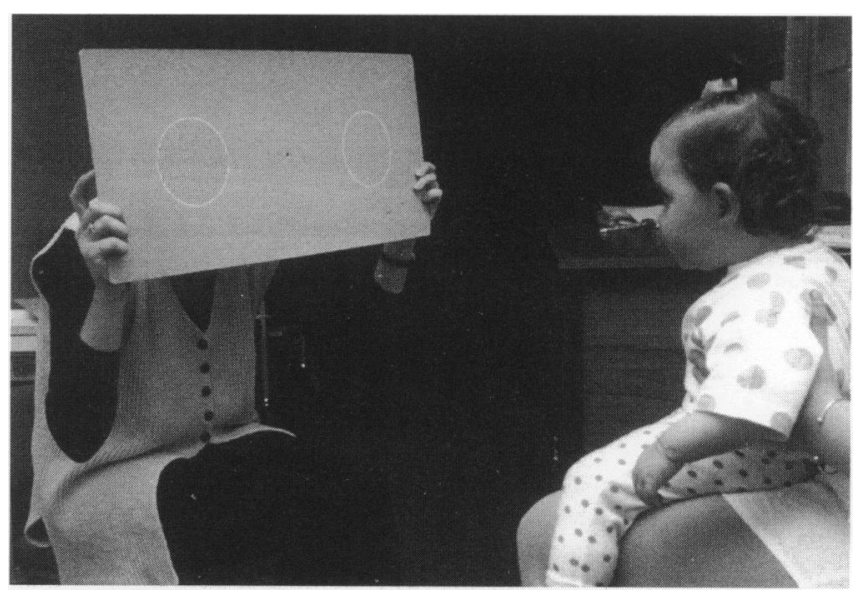

Figure 1 Preferential looking using acuity cards. 
Table 2 Use of preferential looking techniques in the visual assessment of multiply handicapped children: a summary of the literature

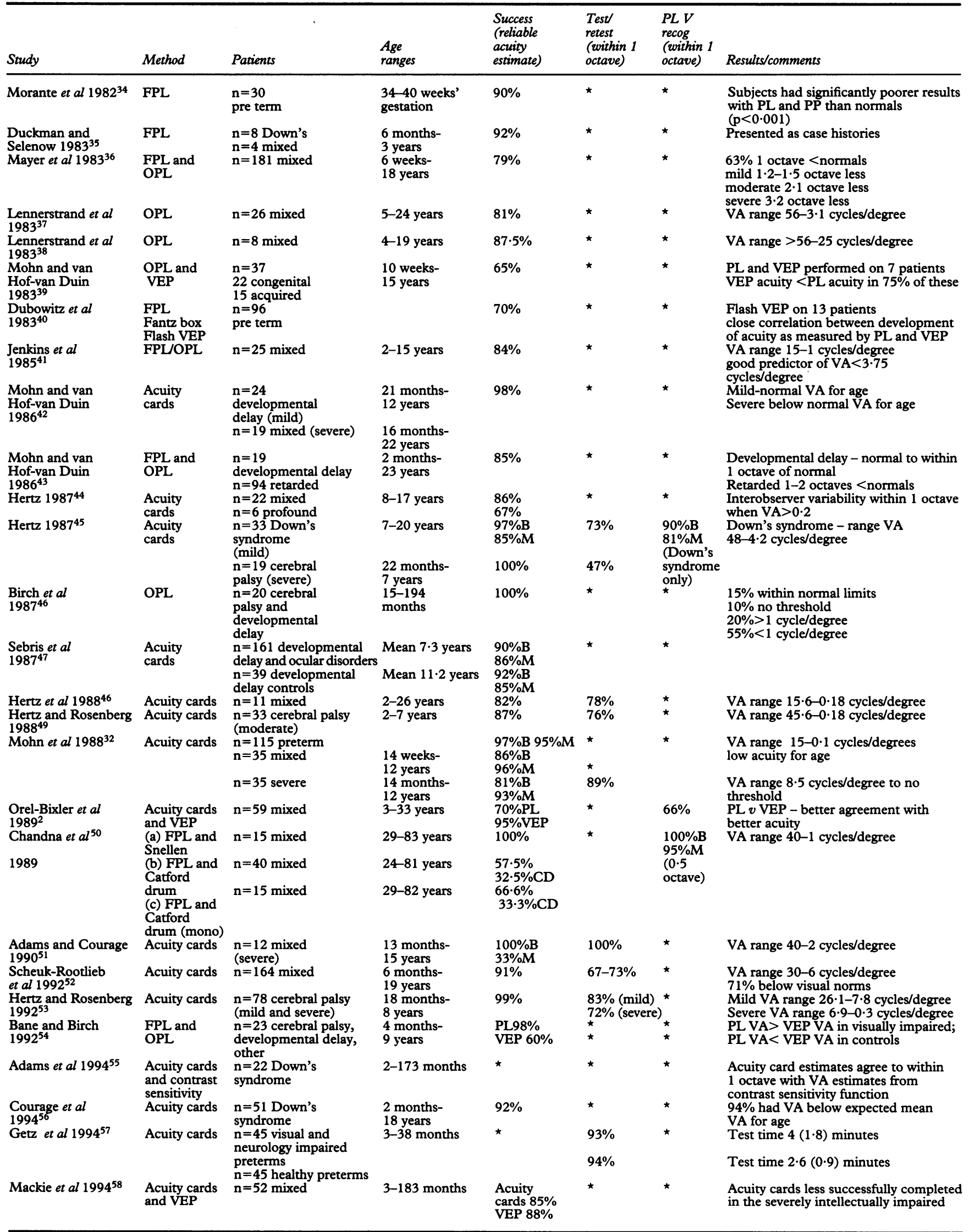

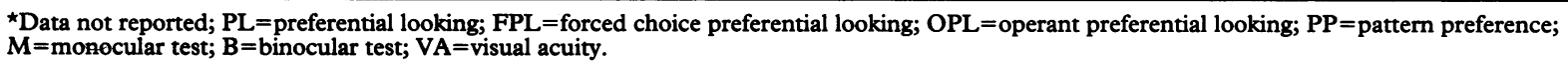

with FPL estimates and repeatability is high. ${ }^{28} 30$ The PL technique has been modified to produce the acuity card procedure. This clinical procedure, developed by McDonald et al is a simpler and quicker method of assessment. ${ }^{31}$ Instead of the observer making an objective assessment of the child's eye movements to achieve a statistical threshold, a subjective interpretation of the child's looking behaviour is made to determine whether the child has seen the target. The acuity card procedure gives results with good agreement and similar variability to 
FPL or OPL, and is considered to be a comparable technique. ${ }^{31} 32$ In all future discussion PL will be taken to indicate all forms of PL unless specified.

Expected mean PL thresholds for normal children range from $1 \cdot 1$ cycles/degree at 1 week $^{33}$ with maturation to adult levels of acuity of 30 cycles/degree by 36 months. ${ }^{31}$ Abnormal thresholds are commonly reported in terms of octaves above expected levels, where each octave represents a doubling of stripe width.

Since 1982, PL techniques have been reported in at least 28 studies of multiply handicapped children, as summarised in Table 2. Early studies have used mainly FPL and OPL on small numbers of individuals. More recently, the increased use of the flexible acuity card technique has provided more complete information regarding acuity thresholds and repeatability. This technique is obviously more suited to the diversity of ability encountered in the multiply handicapped population.

\section{SUCCESS RATES}

Success rates for obtaining a binocular acuity threshold by means of one of the PL techniques vary between $57 \cdot 5 \%$ and $100 \%,{ }^{51}$ with the majority of studies reporting success rates over $70 \%$ (see Table 2 ). Thresholds are commonly expressed either as grating acuity estimates (cycles/degree) or as octave loss compared with age-matched normals (see Appendix). These thresholds are preferred to Snellen equivalents as letter recognition thresholds may be lower than grating thresholds in some groups. ${ }^{59}$ Monocular testing has been attempted in two studies, on a group of children with Down's syndrome ${ }^{45}$ and a mixed group of children who were also capable of reading the Snellen chart ${ }^{50}$; both groups were classed as being mildly intellectually impaired. The majority of studies probably favour binocular testing because of lack of cooperation when an eye is occluded, and the limited value of knowledge of monocular acuities for functional management of the child.

Repeatability is an important variable to ensure the reliability of a technique. Studies which have retested children using acuity cards have reported good repeatability. ${ }^{32} 4952$ However, both severely physically and intellectually impaired children show poorer test reliability than mildly impaired children. These differences are attributed to greater difficulty in interpreting the responses of severely physically impaired children, and higher incidence of oculomotor dysfunction. ${ }^{53}$ Severely intellectually impaired children have extremely variable attentiveness and may show greater day to day differences in performance, mood, and cooperation than more able children. Hence, variable test results may represent variability in the child rather than variability in the testing procedure. ${ }^{53}$ Three studies have investigated the agreement between PL acuity and letter acuity. ${ }^{24550}$ Agreement to within 1 octave varies from $66 \%-100 \%$.

\section{PL AND TYPE OF HANDICAP}

Over half of the studies report mixed types of handicap with a very wide range of visual acuities (for example, $3 \cdot 1$ to 56 cycles/degree ${ }^{37}$ ). The disadvantage of reporting acuity results without defining type of handicap or the level of physical or intellectual disability is that no information is provided to relate vision with the type or severity of the diverse handicaps involved. Multiply handicapped children can have normal visual acuity $3738454648-52$ but detailed studies have consistently found that visual acuity varies inversely with the level of intellectual impairment. ${ }^{32} 36424353$ As would be expected, children with more severe neurological damage and intellectual impairment are more likely to have also suffered damage to the visual pathway.

PL studies using defined groups of handicapped children include developmental delay, Down's syndrome, and cerebral palsy. The majority of subjects with developmental delay and Down's syndrome, who are considered to be mildly intellectually and physically impaired, are reported to demonstrate normal or near normal acuity. ${ }^{42} 4345$ However, recent studies which have investigated contrast sensitivity function and accommodation of children with Down's syndrome have found both functions to be poorer than in normals. ${ }^{20} 55$ Good visual acuity, therefore, does not preclude the presence of other visual dysfunction which may affect developmental progress.

Although all children with cerebral palsy have a motor deficit associated with a static defect or lesion of the brain, this group is extremely heterogeneous. ${ }^{52}$ Physical impairment may be associated with severe intellectual impairment but some children may have a high IQ. ${ }^{60}$ Similarly, a very large range of visual acuities are reported for this group. ${ }^{454648}$ However, the age ranges of the children examined are also large (22 months -7 years $\left.{ }^{45}\right)$. Thus, no general conclusion can be drawn about the level of visual acuity in cerebral palsy. Hertz and Rosenberg studied children with cerebral palsy in more detail and reported poorer visual acuity in those with more severe physical and intellectual impairment (6.9-0.3 cycles/degree). ${ }^{53}$

The PL technique has been established as a valid method of visual acuity assessment of multiply handicapped children, enabling an acuity threshold to be achieved in previously 'untestable' children. However, PL acuity assessment should always be interpreted within the limitations of the testing procedure. In these populations there is a high prevalence of oculomotor disorders and visual field defects. ${ }^{3-59}$ PL acuity estimates can be adversely affected by abnormal eye movements and strabismus which make looking behaviour difficult to assess. The presence of a hemianopic field defect, which is a common finding, can also be a factor as PL stimuli are presented off the visual axis and the stimulus area is relatively small. Presenting the stimulus cards vertically facilitates testing of children with dysfunctional horizontal eye movements and/or hemianopic field defects. ${ }^{32} 53$ Most importantly, the absence of a response to the stimulus may be due to non-visual factors and does not necessarily indicate absence of visual function. An inability to control eye movements sufficiently to produce a looking response, an inability to convert visual input to motor output, and withdrawn behaviour can all produce a negative PL response. These factors may act in a general way or may play an increasing role as the stimulus approaches threshold. ${ }^{61}$

\section{Visual evoked potentials}

\section{TESTING PROCEDURES}

The visual evoked potential (VEP) is a bioelectrical signal generated in the visual cortex of the brain in response to visual stimulation. The stimulus can be either a repeating flash of light (flash VEP); a pattern which is presented repetitively from a luminance matched grey background (pattern onset VEP); or a phase alternated pattern (pattern reversal VEP). The patterns used are typically either checkerboards or sinusoidally modulated gratings. A transient signal results from stimuli, either a flash or a pattern, presented at a slow rate $(<2 \mathrm{~Hz}) .{ }^{62}$ Flash or pattern reversal stimulation presented at higher 


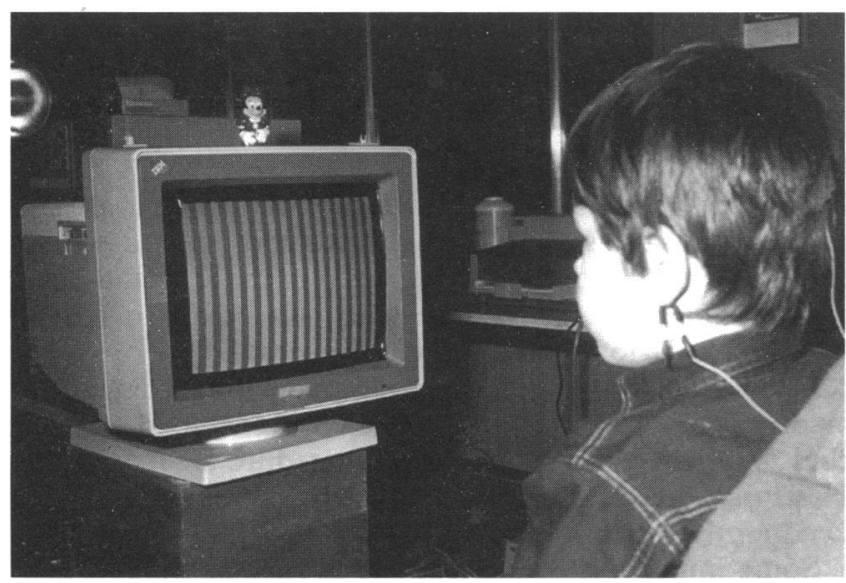

Figure 2 Visual acuity assessment using visual evoked potentials.

frequencies $(6-8 \mathrm{~Hz})$ produces a 'steady state' signal. ${ }^{63}$ The high repetition rate of the stimulus results in an overlap of the VEP waveforms so that a 'steady state' response occurs.

Both transient and steady state techniques can be used to determine visual acuity by measuring the VEP to patterns of different sizes. A VEP is recorded to each stimulus size. Threshold is determined by linear extrapolation of the VEP amplitude versus size function to zero microvolts, ${ }^{63}$ or by determining the minimum size stimulus which produces a reproducible VEP. ${ }^{64} \mathrm{~A}$ further development of the steady state VEP is the swept spatial frequency VEP, or sweep $\mathrm{VEP},{ }^{65}$ in which the stimulus pattern is reversed and simultaneously increased or decreased in size (the pattern is 'swept' up or down in spatial frequency). The display appears as gratings which are reversing in contrast and changing in size simultaneously, so that a range of sizes are presented in a single recording (see Figure 2). Visual acuity threshold is calculated from the signal to noise ratio which provides a more rapid method of acuity estimation. ${ }^{65}$

Both transient and steady state VEPs have been used successfully for assessing visual acuity in infants since 1976. ${ }^{66}$ The sweep technique was introduced more recently. ${ }^{67}$ Pattern reversal and sweep VEP thresholds mature rapidly to within 1 octave of adult values by 6 months of age. ${ }^{65-71}$ Maturation proceeds more slowly thereafter. Sweep and steady state VEP acuity thresholds are typically 14-20 cycles/degree for 8-month-old infants compared with 30 cycles/degree in adults. Transient VEPs produce thresholds of 6 cycles/degree or better in normal infants of a similar age. ${ }^{70} 72$

\section{SUCCESS RATES}

A small number of studies have reported high success rates for VEP examination of multiply handicapped children. Skarf and Panton report success rates of $50-75 \%$ with pattern reversal stimuli in handicapped children under 5 years $(n=150)$, and $67 \%$ in children under 1 year $(\mathrm{n}=64) .{ }^{73}$ Saunders et al used pattern onset VEPs to assess a profoundly handicapped group with Retts syndrome $(n=11)$ who were behaviourally unresponsive to $P L$ stimuli. ${ }^{74}$ VEP acuity thresholds were achieved in $91 \%$ of the group and all had acuities better than 1.25 cycles/degree. Odom and Green concluded that pattern onset VEPs were as successful, or more successful than other procedures for assessing acuity of multiply handicapped children $(n=23) .{ }^{75}$

Some studies have compared acuity estimates from VEPs with those achieved with other tests. Using pattern onset stimuli VEP acuities have been reported as closely correlated with, but consistently lower than, acuity card estimates $(n=52) .{ }^{58}$ Similarly, pattern reversal VEPs are also reported as producing lower acuity estimates than OPL $(n=3)^{39}$ and FPL $(n=23) .{ }^{54}$ Bane and Birch ${ }^{54}$ suggest that this may have been due the presence of central field loss in the visually impaired children examined which is known to degrade VEP amplitude. ${ }^{76}$ Sweep VEPs also produce high success rates $(95 \% ;>90 \%),{ }^{277}$ and close agreement with acuity cards (within 1 octave in $66 \%$ of cases) ${ }^{2}$ and optotype acuities. ${ }^{77}$ However, the sweep VEP acuity estimates tend to be higher than those obtained with other acuity tests.

VEPs provide reliable estimates of visual acuity in children without neurological deficits. In multiply handicapped children, nystagmus, central scotomas and poor fixation are prevalent. These conditions are known to impair VEP quality, making acuity assessment difficult and leading to conservative estimates of acuity. ${ }^{75} 78$ Artefacts from muscle spasticity and/or high background levels of the electroencephalogram can also degrade the VEP. The accuracy and the degree of confidence with which VEPs may be used to estimate acuity in multiply handicapped children is difficult to evaluate from the small number of studies available. However, success rates for completion of the test procedures are high even in the severely and profoundly handicapped children who are generally visually unresponsive. ${ }^{5874}$ This is certainly their main advantage, and with further research and improvement of testing procedures the accuracy of recordings may well improve.

COMPARISON OF PL AND VEP

In the studies discussed above, VEP acuities determined with pattern onset and pattern reversal stimuli are lower than PL acuities, 395458 and acuities determined with sweep VEP stimuli are higher. ${ }^{2} 77$ Inherent differences in the stimulus presentation and scoring procedures of PL and VEP techniques may produce this disparity. One consideration is the different temporal properties of the stimuli used in PL (stationary) and VEP (contrast reversal) paradigms. Comparisons of PL and VEP techniques on normal infants with identical phase alternating gratings by Sokol et al showed better agreement between the thresholds achieved, but the VEP acuity was higher than PL acuity. ${ }^{72}$ In contrast, Dobson et al report no difference between PL acuities measured with stationary and phase alternating checkerboards. ${ }^{79}$ As the majority of the studies reviewed here reported lower VEP acuities than PL acuities stimulus motion is probably not a factor. The higher sweep VEP acuities reported probably arise primarily from the more generous method of scoring employed with sweep VEPs.

Comparison of PL and VEPs is further complicated in multiply handicapped children. The various visual conditions which are common in these children may adversely affect the PL and VEP thresholds to a greater or lesser extent. More contamination of the VEP response would lead to more conservative acuity estimates. Another factor is the more complex level of cortical processing required by the PL response compared with the VEP. While both tests examine the integrity of the visual pathway from retina to the visual cortex, a looking response also involves association and motor cortices. This may lead to lower PL acuity estimates than VEP estimates.

\section{RELATED STUDIES}

VEPs have been used to investigate visual function of multiply handicapped children without specifically addressing visual acuity. While the concern of this paper is 
visual acuity assessment, this work merits a brief discussion.

Cortical visual impairment (CVI), a visual deficit which is not explained by defects in the eye of anterior visual pathways, is common in multiply handicapped children. ${ }^{80}$ VEPs have been employed both to investigate the integrity of the visual pathway and visual cortex in these children and to predict visual and/or neurological outcome. VEP results can differ from clinical results which indicate loss of all visual sensation. Normal VEPs to a flash stimulus have been recorded in some cortically blind children. ${ }^{81} 82$ Frank and Torres found no significant difference in the VEP waveforms to flash stimulus of neurologically impaired children with and without CVI. ${ }^{83}$ It has been suggested that these results are due to the preservation of primary visual cortex in the absence of visual association areas, ${ }^{8283}$ or the presence of extrageniculocalcarine pathways from which the VEP is recording. ${ }^{81} 84$ Pattern reversal VEPs are reported as either abnormal or absent in children with CVI. ${ }^{84-86}$ Flash VEPs appear to have limitations in characterising visual disturbance in CVI, but pattern VEP paradigms appear to be more diagnostic. In children sustaining perinatal asphyxia flash VEPs recorded in the early postnatal period show high predictive value for long term visual $(88 \%)^{17}$ and neurological outcome (94-100\%). ${ }^{87} 88$

\section{Other visual assessment tests}

\section{OPTOKINETIC NYSTAGMUS}

Optokinetic nystagmus (OKN) is a physiological nystagmus elicited by a series of moving objects (for example, stripes), passing across the visual field. It consists of two components: a slow pursuit phase where the eye follows the target, and a fast saccade in the opposite direction to pick up the target again. If a target of suitable size and speed is presented OKN occurs involuntarily. Visual resolution is estimated by the width of the narrowest stripe eliciting OKN.

$\mathrm{OKN}$ has been used to measure infant vision, and a close correlation between $\mathrm{OKN}$ acuity and letter acuity has been found. ${ }^{89} 90$ However the technique has not been widely used in the handicapped population. Wyngaarden et al investigated the relation between the extent of developmental delay and grating acuity using both OKN and PL in 95 children (5-69 months). ${ }^{91}$ They found a moderate but significant correlation between OKN acuity and cognitive performance $(p<0.5)$, but did not compare the $\mathrm{OKN}$ acuities with other measures of acuity. The relation between the presence of $\mathrm{OKN}$ and visual function has been investigated in several studies. ${ }^{92-95}$ In these, children with no previously measurable visual function showed positive, but not necessarily normal, OKN $\left(10 \%,{ }^{92} 69 \%, 9350 \%,{ }^{94} 100 \%,{ }^{94}\right.$ and $30 \%{ }^{96}$ of subjects). Some patients with visual loss due to cortical damage may retain brainstem reflex visual responses and therefore perform $\mathrm{OKN}$, but do not consciously see the target. They may also display visual navigation skills (blindsight). Conversely, some children with measurable visual function have been shown to demonstrate no OKN response, when measured subjectively $(9 \%)$ or objectively $(19 \%) .{ }^{94}$ Nearly all of these subjects demonstrated spontaneous or latent nystagmus which was judged to have affected the results by obscuring any OKN. Visual field defects are also thought to reduce the $\mathrm{OKN}$ response as the affected patients have less visual stimuli to pursue: one study reported visual field defects in $60 \%$ of the subjects but these defects were not classified. ${ }^{93}$

The relation between visual function and $\mathrm{OKN}$ is complex in children with neurological disorders. It may be misleading to use $\mathrm{OKN}$ as a visual acuity test but it is a very useful indicator of brainstem visual function.

\section{Conclusion}

Both PL and VEP techniques provide quantitative measures of visual acuity and are likely to be successfully completed by multiply handicapped children. In the past, clinical judgment of visual acuity for many of these children relied only on a qualitative evaluation of visual behaviour. PL and VEP techniques have been adopted in many specialist centres and are often available in routine clinical practice. The acuity card procedure for measuring PL acuity is particularly accessible as it is easy to learn and to administer.

Some important considerations should be made when interpreting PL or VEP acuities from an individual patient. The first is the reliability of the measurement. Where intrasession reliability has been evaluated, results in most handicapped children are reproduced within 1 octave. ${ }^{32} 5153$ However, like most other clinical assessments, reliability is reduced among the severely and profoundly handicapped. Since variable attentiveness, poor fixation, motor handicap, and oculomotor abnormalities contribute to poor reliability, a single acuity measurement may be reliable only to within 2 or 3 octaves when these factors are present.

Secondly, the visual stimuli for VEP and PL acuity require pattern resolution whereas conventional visual acuity is a letter recognition task. In a normal adult visual system, the thresholds for pattern resolution (also called grating acuity) and letter recognition at the fovea are equivalent, and there is a temptation to convert pattern resolution visual acuity to familiar Snellen visual acuity units (see Appendix). However, different neural substrates are involved in pattern resolution and letter recognition so that these thresholds can be very different - for example, in amblyopia or in the normal peripheral retina. ${ }^{97}$ Pattern resolution is necessary to enable recognition but it is certainly not sufficient to assume that recognition would occur particularly in the handicapped population where perceptual dysfunction is common. ${ }^{96}$

In many situations, a handicapped child is assessed to determine how well he or she can 'see'. Seeing implies resolution, recognition, and conscious perception but the techniques reviewed here measure resolution only. VEP acuity is a measure of the ability of the visual system to resolve and transmit information about a particular pattern size to the level of the visual cortex. PL acuity demonstrates these functions as well as the ability to attend and make a motor response. Poor pattern resolution acuity gives a poor prognosis for recognition acuity but good pattern resolution acuity does not necessarily indicate a good prognosis for recognition. There are currently no quantitative techniques for measurement of recognition acuity or perception in children who are unable to complete letter matching tasks. A clinical judgment of these functions must be made before making recommendations for social services support or educational intervention. ${ }^{98}$

The present literature is adequate to support the use of PL and VEP visual acuity techniques to assess the acuity of multiply handicapped children. The techniques give complementary information and completion of both allows a more informed assessment of resolution visual acuity. Future studies are needed to improve interpretation when specific adverse conditions, such as oculomotor dysfunction or visual field defects are concurrent. In addition, the association between specific aetiological factors and expected visual acuity needs elucidation. 
We thank Dr G N Dutton and Dr K J Saunders for their helpful comments and suggestions on the manuscript. Support is received from the chief scientist's suggestions on the manuscript. Support is received from the chief scientist's
office, Disability Research Committee, Scottish Office Home and Health office, Disability Research Committee, Scottish Office Home and Health
Department (K/RED/4/C183). Roisin Mackie is the current Elizabeth Murray Memorial scholar of the Vision Research Trust.

\section{ROISIN T MACKIE}

Department of Vision Sciences,

Glasgow Caledonian University,

Cowcaddens Road,

Glasgow G4 0BA

\section{Appendix}

Conversion of Snellen acuity to cycles/degree and octave loss equivalents

\begin{tabular}{lll}
\hline Snellen & Cycles/degree & Octave loss \\
\hline $6 / 6$ & 30 & 0 \\
$6 / 12$ & 15 & 1 \\
$6 / 18$ & 10 & $1 \cdot 6$ \\
$6 / 24$ & $7 \cdot 5$ & 2 \\
$6 / 36$ & 5 & $2 \cdot 6$ \\
$6 / 48$ & $3 \cdot 75$ & 3 \\
$6 / 60$ & 3 & $3 \cdot 3$ \\
$6 / 90$ & 2 & $3 \cdot 9$ \\
$6 / 120$ & 1.5 & $4 \cdot 3$ \\
$6 / 240$ & 0.75 & $5 \cdot 3$ \\
$6 / 480$ & 0.375 & $6 \cdot 3$ \\
\hline
\end{tabular}

*Octave loss is measured relative to expected visual acuity for the appropriate age. The values given here are for children over 4 years of age with an expected visual acuity of $6 / 6$ Snellen.

1 Lawson Jr JL, Schoofs G. A technique for visual appraisal of mentally retarded children. Am $\mathcal{f}$ Ophthalmol 1974; 72: 622-4.

2 Orel-Bixler D, Haegerstrom-Portnoy G, Hall A. Visual assessment of the multiply handicapped patient. Optom Vis Sci 1989; 66: 530-6.

3 Jacobson L. Ophthalmology in mentally retarded adults. Acta Ophthalmol 1988; 66: 457-62.

4 Scheimann $M$. Optometric findings in children with cerebral palsy. Am f Optom Physiol Opt 1984; 61: 321-3.

5 Kennerly Bankes JL. Eye defects of mentally handicapped children. BMF 1974; 2: 533-5.

6 Lyle W, Woodruff ME, Zuccaro VS. A review of the literature on Down's syndrome and an optometrical survey of 44 patients with the syndrome. syndrome and an optometrical survey of 44 patients

7 Roizen NJ, Mets MB, Blondis TA. Ophthalmic disorders in children with Down syndrome. Dev Med Child Neurol 1994; 36: 594-600.

8 Woodruff ME, Cleary TE, Bader D. The prevalence of refractive and ocular anomalies among 1242 institutionalized mentally retarded persons. Am f Optom Physiol Opt 1980; 57: 70-84.

9 Black P. Visual disorders associated with cerebral palsy. Br f Ophthalmol 1982; 66: 46-52.

10 LoCascio GP. A study of vision in cerebral palsy. Am f Optom Physiol Opt 1977; 54: 332-7.

11 Maino DM, Maino JH, Maino SA. Mental retardation syndromes with associated ocular defects. $\mathcal{Y}$ Am Optom Assoc 1990; 61: 707-16.

12 Gallo JE, Lennerstrand G. A population-based study of ocular abnormalities in premature children aged 5 to 10 years. Am $\mathcal{F}$ Ophthalmol 1991; 111: $539-47$.

13 Keith CG, Kitchen WH. Ocular morbidity in infants of very low birth weight. Br f Ophthalmol 1983; 67: 302-5.

14 Gibson NA, Fielder AR, Trounce JQ, Levene MI. Ophthalmic findings in infants of very low birthweight. Dev Med Child Neurol 1990; 32: 7-13.

15 Pike MG, Holmstrom G, De Vries LS, Pennock JM, Drew KJ, Sonksen PM, et al. Patterns of visual impairment associated with lesions of the preterm infant brain. Dev Med Child Neurol 1994; 36: 849-62.

16 Groenendaal F, van Hof-van Duin J, Baerts W, Fetter WPF. Effects of perinatal hypoxia on visual development during the first year of (corrected) natal hypoxia on visual development during the

age. Early Human Development 1989; 20: 267-79.
17 McCulloch DL, Taylor MJ, Whyte HE. Visual evoked potentials and visual prognosis following perinatal asphyxia. Arch Ophthalmol 1991; 109: 229-33.

18 Harcourt B. Strabismus affecting children with multiple handicaps. Br f Ophthalmol 1974; 58: 272-80.

19 Warshowsky J. A vision screening of a Down's syndrome population. f Am Optom Assoc 1981; 52: 605-7.

20 Woodhouse JM, Meades JS, Leat SJ, Saunders KJ. Reduced accommodation in children with Down syndrome. Invest Ophthalmol Vis Sci 1993; 34: 2382-7.

21 Sonksen PM, Petrie A, Drew KJ. Promotion of visual development of severely visually impaired babies: evaluation of a developmentally based programme. Dev Med Child Neurol 1991; 33: 320-35.

22 Reynell J. Developmental patterns of visually handicapped children. Child Care, Health and Development 1978; 4: 291-302.

23 Warburg $M$. Why are the blind and severely visually impaired children with mental retardation much more retarded than the sighted children? Acta Ophthalmol (Suppl) 1982; 157: 72-8.

24 Duckman R. Effectiveness of visual training on a population of cerebral palsied children. $₹$ Am Optom Assoc 1980; 51: 607-14.

25 Bader D, Woodruff ME. The effects of corrective lenses on various behaviours of mentally retarded persons. Am F Optom Physiol Opt 1980; 57: 447-59.

26 Fantz RL. Pattern vision in young infants. Psychological Record 1958; 8: 43-7.

27 Mayer DL, Fulton AB, Hansen RM. Preferential looking acuity obtained with a staircase procedure in pediatric patients. Invest Ophthalmol Vis Sci 1982; 23: 538-42.
28 Birch EE, Gwiazda J, Bauer Jr JA, Naegele J, Held R. Visual acuity and its meridional variations in children aged 7-60 months. Vision Res 1983; 23: 1019-24.

29 Mayer DL, Dobson V. Assessment of vision in young children: a new operant approach yields estimates of acuity. Invest Ophthalmol Vis Sci 1980; 19: 566-70.

30 Mayer DL, Dobson V. Visual acuity development in infants and young children as assessed by operant preferential looking. Vision Res 1982; 22: 1141-51.

31 McDonald M, Dobson V, Sebris SL, Baitch L, Varner D, Teller DY. The acuity card procedure: a rapid test of infant acuity. Invest Ophthalmol Vis Sci 1985; 26: 1158-62.

32 Mohn G, van Hof-van Duin J, Fetter WP, de Grot L, Hage M. Acuity assessment of non-verbal infants and children: clinical experience with the assessment of non-verbal infants and children: clinical experience

33 van Hof-van Duin J, Mohn G. The development of visual acuity in normal fullterm and preterm infants. Vision Res 1986; 26: 909-16.

34 Morante A, Dubowitz LMS, Levene M, Dubowitz V. The development of visual function in normal and neurologically abnormal preterm and fullterm infants. Dev Med Child Neurol 1982; 24: 771-84.

35 Duckman RH, Selenow A. Use of FPL for measurement of visual acuity in a population of neurologically impaired children. Am f Optom Physiol Opt 1983; 60: 817-21.

36 Mayer DL, Fulton AB, Sossen P. Preferential looking acuity of pediatric patients with developmental disabilities. Behav Brain Res 1983; 10: patients

37 Lennerstrand G, Axelsson A, Andersson G. Visual acuity testing with preferential looking in mental retardation. Behav Brain Res 1983; 10: 199-202.

38 Lennerstrand G, Axelsson A, Andersson G. Visual assessment with preferential looking techniques in mentally retarded children. Acta Ophthalmol (Copenh) 1983; 61: 183-5.

39 Mohn G, van Hof-van Duin J. Behavioural and electrophysiological measures of visual functions in children with neurological disorders. Behav Brain Res 1983; 10: 177-87.

40 Dubowitz LMS, Mishin J, Morante A, Placzek M. The maturation of visua acuity in neurologically normal and abnormal newborn infants. Behav Brain Res 1983; 10: 39-45.

41 Jenkins PL, Simon JW, Gillray LK, Forster T. A simple grating visual acuity test for impaired children. Am f Ophthalmol 1985; 99: 652-8.

42 Mohn G, van Hof-van Duin J. Rapid assessment of visual acuity in infants and children in a clinical setting, using acuity cards. Doc Ophthalmol Proc Ser 1986; 45: 363-72.

43 Mohn G, van Hof-van Duin J. Preferential looking acuity in normal and neurologically abnormal infants and pediatric patients. Doc Ophthalmol Proc Ser 1986; 45: 221-30.

44 Hertz BG. Use of the acuity card method to test retarded children in special schools. Child Care, Health and Development 1987; 14: 189-98.

45 Hertz BG. Acuity card testing of retarded children. Behav Brain Res 1987; 24: 85-92.

46 Birch E, Hale L, Stager D, Fuller D, Birch D. Operant acuity of toddlers and developmentally delayed children with low vision. 7 Pediatr Ophthalmol Strabismus 1987; 24: 64-9.

47 Sebris SL, Dobson V, McDonald MA, Teller DY. Acuity cards for visual acuity assessment of infants and children in clinical settings. Clin Vis $\mathrm{Sc}$ 1987; 2: 45-58.

48 Hertz BG, Rosenberg J, Sjo O, Warburg M. Acuity card testing of patients with cerebral visual impairment. Dev Med Child Neurol 1988; 30: 632-7.

49 Hertz BG, Rosenberg J. Acuity card testing of spastic children: preliminary results. F Pediatr Ophthalmol Strabismus 1988; 25: 139-44

50 Chandna A, Karki C, Davis J, Doran RML. Preferential looking in the mentally handicapped. Eye 1989; 3: 833-9.

51 Adams RJ, Courage ML. Assessment of visual acuity in children with severe neurological impairments. F Pediatr Ophthalmol Strabismus 1990; 27: 185-9.

52 Schenk-Rootlieb AJF, van Nieuwenhuizen O, van der Graff Y, Wittebol D Willems EJ. The prevalence of cerebral visual disturbance in children with Willems EJ. The prevalence of cerebral visual disturbance

53 Hertz BG, Rosenberg J. Effect of mental retardation and motor disability on testing with visual acuity cards. Dev Med Child Neurol 1992; 34: 115-22.

54 Bane MC, Birch EE. VEP acuity, FPL acuity and visual behaviour of visually impaired children. $\mathcal{F}$ Pediatr Ophthalmol Strabismus 1992; 29: 202-9.

55 Adams J, Courage ML, Hall EJ. Contrast sensitivity in infants and children with Down's syndrome. Invest Ophthalmol Vis Sci 1994; 35: 2030.

56 Courage ML, Adams RJ, Reyno S, Kwa PG. Visual acuity in infants and children with Down syndrome. Dev Med Child Neurol 1994; 36: 586-93.

57 Getz L, Dobson V, Luna B, Mash C. Interobserver agreement for Telle acuity card procedure: tests of children with ocular and neurological abnormalities. Invest Ophthalmol Vis Sci 1994; 35: 1416.

58 Mackie R, McCulloch DL, Saunders KJ, Ballantyne J, Bradnam MS, Day $R$, et al. Comparison of visual assessment tests in multiply handicapped children. Eye 1995; (in press).

59 Levi DM, Klein SA. Differences in Vernier discrimination for grating between strabismic and anisometropic amblyopes. Invest Ophthalmol Vis Sci 1982; 23: 398-407.

60 Lyle WM, ed. Genetic risks: a reference for eye care practitioners. Waterloo: University of Waterloo Press, 1990.

61 Birch EE, Bane MC. Forced-choice preferential looking acuity of children with cortical visual impairment. Dev Med Child Neurol 1993; 33: 722-9.

62 Taylor MJ, McCulloch DL. Visual evoked potentials in infants and children 7 Clin Neurophysiol 1992; 9. 357-72.

63 Sokol S. Measurement of visual acuity from pattern reversal evoked potentials. Vision Res 1978; 18: 33-9.

64 Towle VL, Harter MR. Objective determination of human visual acuity: pattern evoked potentials. Invest Ophthalmol Vis Sci 1977; 16: 1073-6.

65 Regan D. Speedy assessment of visual acuity in amblyopia by the evoked potential method. Ophthalmologica 1977; 175: 159-64.

66 Marg E, Freeman DN, Peltzman P, Goldstein PJ. Visual acuity development in human infants: evoked potential measurements. Invest Ophthalmo 1976; 15: 150-3

67 Norcia A, Tyler C. Spatial frequency sweep VEP: visual acuity during the first year of life. Vision Res 1985; 25: 1399-408.

69 Hamer RD Norcia AM, Tyler CW, Hsu-Winges C. The development of monocular and binocular VEP acuity. Vision Res 1989; 29: 397-408. 
$70 \mathrm{McCulloch}$ DL, Skarf B. Development of the human visual system: monocular and binocular pattern VEP latency. Invest Ophthalmol Vis Sci 1990, 32: $2372-81$.

71 McCulloch DL, Skarf B. Pattern reversal visual evoked potentials following early treatment of unilateral, congenital cataract. Arch Ophthalmol 1994; 112: $510-8$.

72 Sokol S, Moskowitz A, McCormack G. Infant VEP and preferential looking acuity measured with phase alternating gratings. Invest Ophthalmol Vis Sci 1992; 33: 3156-61.

73 Skarf B, Panton C. VEP testing of neurologically impaired and developmentally delayed infants and young children. Invest Ophthalmol 1987; 28 . 302 .

74 Saunders KJ, McCulloch DL, Kerr AM. Visual function in Retts syndrome. Dev Med Child Neurol 1995; (in press).

75 Odom JV, Green $M$. Visually evoked potentials (VEP) acuity. Testability in a clinical pediatric population. Acta Ophthalmol 1984; 62: 993-8.

76 Skalka HW. Comparison of Snellen acuity, VER acuity and Arden grating scores in macular and optic nerve diseases. Br $\mathcal{f}$ Ophthalmol 1980; 64: s4-9.

77 Ver Hoeve JN, Whyte BS, France TD. Correlation between swept spatial frequency VEP acuity and ototype acuity in children with a variety of visual disorders. Invest Ophthalmol 1994; 35: 2028.

78 Apkarian P. Methodology of testing for albinism with visual evoked cortical potentials. In: Heckenlively JR, Arden GB, eds. Principles and practice of clinical vision testing. St Louis: Mosby Year Book, 1991: 425-34.

79 Dobson V, Teller DY, Belgum J. Visual acuity in human infants assessed with stationary stripes and phase-alternated checkerboards. Vision Res with stationary strip

80 Good WV, Jan JE, Desa L, Barkovich AJ, Groenveld M, Hoyt CS. Cortical visual impairment in children. Surv Ophthalmol 1994; 38: 351-64.

81 Whiting S, Jan JE, Wong PK, Flodmark O, Farrell K, McCormick AQ Permanent cortical visual impairment in children. Dev Med Child Neurol 1985; 27: 730-9.

82 Bodis-Wollner I, Atkin A, Raab E, Wolkstein M. Visual association cortex and vision in man: pattern-evoked occipital potentials in a blind boy. Science 1977; 198: 629-31.

83 Frank Y, Torres F. Visual evoked potential in the evaluation of 'cortical blindness' in children. Ann Neurol 1979; 6: 126-9.

84 Kupersmith MJ, Nelson JI, Carr RE. The visual evoked potential as a prognosticator in childhood cortical blindness. Ann Neurol 1983; 14:146.

85 Frank Y, Kurtzberg D, Kreuzer JA, Vaughan HG. Flash and patternreversal visual evoked potential abnormalities in infants and children with cerebral blindness. Dev Med Child Neurol 1992; 34: 305-15.

86 Taylor MJ, McCulloch DL. Prognostic value of VEPs in young children with acute onset of cortical blindness. Pediatr Neurol 1991; 7: 111-5.

87 Muttitt SC, Taylor MJ, Kobayashi JS, MacMillan L, Whyte HE. Serial visual evoked potential and outcome in term birth asphyxia. Pediatr Neurol 1991; 7: 86-90.

88 Taylor MJ, Murphy WJ, Whyte HE. Prognostic reliability of somatosensory and visual evoked potentials of asphyxiated term infants. Dev Med Child Neurol 1992; 34: 507-15.

89 Reinecke RD, Cogan DG. Standardization of objective visual acuity measurements: optokinetic nystagmus vs Snellen acuity. $A M A$ Arch Ophthamol 1958; 60: 418-21.

90 Lewis TL, Maurer D, Brent HP. The development of visual resolution in infants and toddlers tested monocularly with OKN. Clin Vision Sci 1990; 5: $231-41$.

91 Wyngaarden PA, Maurer D, Lewis TL, Harvey P, Rosenbaum P. The relationship between developmental delay and grating acuity. Invest Ophthalmol Vis Sci 1991; 32: 961

92 Van Hof-van Duin J, Mohn G. Visual field measurements, optokinetic nystagmus and the visual threatening response: normal and abnormal development. Doc Ophthalmol Proc Ser 1986; 45: 305-16.

93 Van Hof-van Duin J, Mohn G. Optokinetic nystagmus and visually evoked potentials in functionally blind children - preliminary results. Behav Brain potentials in function

94 Van Hof-van Duin J, Mohn G. Optokinetic and spontaneous nystagmus in children with neurological disorders. Behav Brain Res 1983; 10: 163-75.

95 Westall C. Eye movements in cortically blind children. Optom Vis Sci 1991; 68: 153

96 Dutton G. Cognitive visual dysfunction. Br $\mathcal{F}$ Ophthalmol 1994; 78: 723-6.

97 Thibos LN, Bradley A. New methods for discriminating neural and optical losses of vision. Optom Vis Sci 1993; 70: 279-87.

98 Kushne BJ. Grating acuity tests should not be used for social service purposes in preliterate children. Arch Ophthalmol 1994; 112: 1030-1. 